though there is no complete universal model, there is a great deal of standard lore - correlation functions, newtonian statistical dynamics, relativistic perturbation theory, scaling laws and so on. Peebles avoids the fundamental uncertainties by focusing on manageable physical problems which can be solved to yield precise answers to specific questions. That is perhaps the best that anyone could do given our present state of ignorance.

The authors are at the Astronomy and Astrophysics Center of the University of Chicago.

\title{
Rabbie Burns and the art of genetics
}

\section{Tony Searle}

Genetics and Probability in Animal Breeding Experiments. By Earl L. Green. Pp.271. ISBN 0-333-27243-9/0-19-520159-0. (Macmillan Press, London/Oxford University Press, New York: 1981.) £20, $\$ 36.95$.

IT IS well known that even "the best laid schemes o' mice an' men gang aft a-gley', so the need for this book is obvious. It is meant to minimize the "a-gley factor" where the two species undertake joint genetic enterprises, and it should fulfil its purpose if read as conscientiously as the lectures engendering it were doubtless listened to. They were given by Earl Green when Director of the Jackson Laboratory, to each year's new crop of staff members and postdoctoral fellows. No one who is familiar with the high standards of genetic

\section{SCIENTIFIC BOOKSHOP}

H.K. LEWIS can supply works in all branches of Pure and Applied Science. Catalogues on request. Please state interests.

\section{SCIENTIFIC LENDING LIBRARY}

Annual Subscription from $\mathbf{E 7 . 5 0}$. (Available in U.K. only')

Reduced rates for multiple subscriptions.

\section{Prospectus post free on request.}

Quarterly List of New Books and new editions added to the Library sent post free to subscribers regułarly.

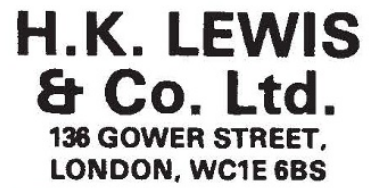

research and animal breeding at that laboratory can doubt their effectiveness.

Amidst all the marvels of somatic cell hybridization, probes, DNA sequencing and the like, the more humdrum procedures of constructing and maintaining inbred strains for particular purposes, introducing mutant genes into them, studying newly arisen mutants and finding where they belong in the genome must go on. In the past, the necessary expertise has had to be acquired piecemeal and often belatedly; now it is all gathered together in one volume. I could have done with such a vade-mecum 30 years ago, but it (and I) would have been slimmer then. Thus, there is now full coverage of how to produce and use recombinant inbred strains, which have proved so valuable in recent years, and of modern methods of linkage analysis. In fact, the chapters "Linkage, Recombination and Mapping"' and "Mating Systems", with associated appendices (for example on maximum likelihood methods) take up nearly half the book.

J.B.S. Haldane used to punctuate his genetics lectures with "Let me give you an example" and Earl Green uses the same idea liberally in this book. Matings of mice with pale ears and dilute coats illustrate probabilities, tests of significance, symbolism, gametic output and so on, other matings illustrate linkage and still others demonstrate the use of Finney's scores for linkage and analysis. These help a lot in what would otherwise be a harder slog. All the examples are based on mice but of course the book as a whole should be a boon to all mammals in search of a genome. The mouse is far ahead of the rest at present, but with modern mutagenic methods the gap could be narrowed quite rapidly.

Among the ten appendices are the complete rules of nomenclature for mouse genes and inbred strains, as well as the author's system of record-keeping and a recommended mouse-room layout. My only regret is that there is so little on how to deal with translocations and other chromosome anomalies. There are a lot of them about nowadays and, with some types of cross, they can play havoc with Mendelian genetics.

A.G. Searle is in the Genetics Section at the Medical Research Council's Radiobiology Unit, Harwell.

\section{Spectroscopic sound}

\section{J. Adams}

Photoacoustics and Photoacoustic Spectroscopy. Chemical Analysis, Vol. 57. By Allan Rosencwaig. Pp.324. ISBN 0-47104495-4. (Wiley: 1981.) £19, \$43.75.

THE photoacoustic effect (prior to 1977 more commonly termed the optoacoustic effect) provides the basis for a calorimetric method of measuring the absorption of electromagnetic radiation by a sample under study. The phenomenon may be applied to many spectroscopic and nonspectroscopic studies involving the interaction of radiation with matter. $\mathrm{Dr}$ Allan Rosencwaig, internationally recognized as a pioneer in the modern development of photoacoustic techniques, has attempted to bring together in this book a comprehensive review of the theory and current applications of methods employing the effect.

In the first two chapters the author presents a brief summary of the phenomenon and describes its study up to the last decade. Until quite recently the majority of applications of photoacoustic spectroscopy (PAS) have been limited to the study and analysis of gaseous systems, and six chapters (approximately a quarter of the book) are given over to this work. The theory and more common experimental arrangements for gaseous PAS are discussed and a chapter is devoted to a review and evaluation of suitable radiation sources for PAS. Applications of PAS to the study of gases, including multicomponent analysis, de-excitation studies, high resolution spectroscopy, photolysis and non-linear effects, are examined.

Much of this first part of the book is already available in many excellent reviews and serves here only as a background and introduction to the remainder of the text which covers the application of photoacoustic studies to the examination of condensed-phase media. It is in the contents of these 15 chapters that the author's own contributions are predominant and which provide the book with its special interest. A chapter is devoted to the general theory of the photoacoustic effect employing gas-microphone systems and piezoelectric transducers, and another, of five pages, provides a simplified theoretical account for those who might find the more rigorous treatments, derived in previous sections, demanding. Experimental systems and apparatus for the examination of solid and liquid samples are reviewed and a chapter is reserved for the more novel spectroscopic studies, including dichroism and Fourier transform techniques. The areas of condensed-phase sample PAS reviewed comprise chemical studies, surface studies and applications in biology and medicine. De-excitation phenomena in solid and liquid media, including fluorescence 